\title{
GUERRA, AGRESIONES A EMBAJADAS Y PREJUICIOS DE GÉNERO EN LA EXPANSIÓN ROMANO-REPUBLICANA: EL CASO DE TEUTA DE ILIRIA*
}

\author{
WAR, AGGRESSIONS AGAINST EMBASSIES AND GENDER PREJUDICE DURING \\ THE EXPANSION OF THE ROMAN REPUBLIC: THE CASE OF TEUTA OF ILLYRIA
}

POR

ENRIQUE GARCÍA RIAZA**

\section{Resumen - ABstract}

Durante la expansión romano-republicana, la agresión contra misiones diplomáticas fue recurrentemente considerada como motivo para la declaración de guerra. El presente trabajo ofrece un examen de las referencias literarias al respecto, que son analizadas en el contexto de la historia de la diplomacia antigua. Se presta especial atención, como estudio de caso, a los supuestos crímenes contra el ius legationis cometidos en el 230 a. C. por Teuta, regente de Iliria, en los que confluyen, también, interpretaciones sesgadas por la condición femenina del personaje.

During the expansion of the Roman Republic, aggression against diplomatic missions was repeatedly regarded as grounds for the declaration of war. This paper provides an examination of the literary evidence alluding to this issue, which is analysed in the context of the history of ancient diplomacy. Special attention is paid, as a case study, to the alleged crimes against ius legationis committed in $230 \mathrm{BC}$ by Teuta, regent of Illyria, in which converge, also, interpretations biased by the female condition of this ruler.

\section{Palabras Clave - Keywords}

Guerra; diplomacia; ius legationis; República romana; Iliria; Teuta.

War; diplomacy; ius legationis; Roman Republic; Illyria; Teuta.

\section{Cómo citar este ARTículo / Citation}

García Riaza, E. (2020): «Guerra, agresiones a embajadas y prejuicios de género en la expansión romanorepublicana: el caso de Teuta de Iliria». Gladius, 40: 7-17. https://doi.org/10.3989/gladius.2020.01

En el ámbito de la expansión romana, la aplicación de la violencia contra embajadores y otros enviados oficiales representa un capítulo no menor en el argumentario para la declaración de guerra. La inviolabilidad de los heraldos y, por extensión, de los emisarios diplomáticos constituye una convención ampliamente extendida en el mundo antiguo ${ }^{1}$. Dadas las profundas

* Trabajo realizado en el ámbito del Proyecto PGC2018-096415-B-C21, Subproyecto C22 «La expresión diplomática en el Mediterráneo central y oriental bajo la expansión romana: el regalo en su contexto político e institucional», subvencionado por la Agencia Estatal de Investigación, Gobierno de España.

** Universitat de les Illes Balears, garcia.riaza@uib.es / ORCID iD: http://orcid.org/0000-0003-4085-2323

1 Philipson, 1911: 302-346; Bederman, 2001: 88-119. 
relaciones entre el concepto de fides y la esfera religiosa ${ }^{2}$, los crímenes contra el ius legationis resultaban especialmente execrables ${ }^{3}$. Quizás por ello, nuestras fuentes $-\mathrm{y}$, en última instancia, las instituciones responsables de la declaración de guerra- acuden con frecuencia a tales justificaciones para la ruptura de hostilidades. Diversos trabajos se han centrado en esta problemática, siendo especialmente sugerente el debido a Broughton ${ }^{4}$. Este autor - sobre el que volveremos a lo largo del artículo - analiza el reducido número de casos registrados de maltrato a misiones diplomáticas en suelo itálico, y estudia también el papel de los feciales -bien conocido, por otra parte, en la declaración de guerra y conclusión de tratados -5 en lo relativo a su capacidad legal para solicitar la extradición y juzgar a los sospechosos de tales agresiones. En su obra, Broughton se centra en tres episodios. El primero de ellos, que podría datarse en torno al 266 a. C., nos llega a través de la referencia de las Periochae ${ }^{6}$ al riesgo de agresiones que afrontaron en Italia los miembros de la legatio de Apolonia, teniendo que viajar desde Roma a Brindisi protegidos por una escolta. El segundo corresponde al 188 a. C., en el contexto de las relaciones romano-púnicas? ${ }^{7}$ Se trata de un pasaje alusivo a L. Minucio y L. Manlio, a los que se acusó en Roma de haber golpeado a embajadores cartagineses (en Valerio Máximo: quia manus his attulerant). En consecuencia, los feciales, cumpliendo órdenes del pretor, llevaron a cabo su entrega a Cartago. El tercero, transmitido únicamente por Diodoro de Sicilia ${ }^{8}$, dataría entre el 103 y el 100 a. C., y tendría como protagonista una legatio enviada a Roma por Mitrídates. Los integrantes de esta fueron duramente acusados por L. Apuleyo Saturnino de portar grandes sumas en metálico para sobornar al senado. Los legati protestaron, a su vez, por el tono agresivo y las imputaciones de Saturnino. Con el respaldo del senado, las reclamaciones de los emisarios fueron atendidas, y se llevó a cabo un juicio público, en el que el colegio de feciales pudo tener protagonismo. Saturnino, contando con el apoyo popular, sería finalmente absuelto.

El trabajo de Broughton constituye, en definitiva, un excelente punto de partida para nuestros propósitos, al confrontar el maltrato en suelo itálico a misiones diplomáticas extranjeras con la propia tradición romana de la fides. No obstante, el objetivo del presente estudio es justamente el complementario, dado que se centra en aquellos casos que tuvieron como víctimas a enviados romanos. Para el desarrollo de esta aproximación al tema resulta de especial utilidad el análisis llevado a cabo por Brennan a partir de la compilación de textos comisionada en el siglo X por Constantino VII Porfirogénito9. Esta obra bizantina, conocida comúnmente como De legationibus, ha llegado prácticamente íntegra hasta nuestros días, y ofrece una amplia información correspondiente a época republicana y altoimperial obtenida de fuentes diversas, entre las cuales Polibio, Diodoro o Apiano. Las noticias de las misiones diplomáticas recogidas en los Excerpta se agrupan bajo dos grandes epígrafes: «Embajadas del pueblo romano a pueblos extranjeros» y su complementario, mucho más prolijo en entradas e información. A lo largo del estudio en torno a las posibilidades de este extraordinario documento, Brennan reflexiona sobre la práctica ausencia de noticias de embajadas fallidas mencionadas en el registro epigráfico, y llama la atención acerca del elevado porcentaje (rondando el 50 \%)

\footnotetext{
2 Boyancé, 1964.

3 Entre la amplia bibliografía sobre las atribuciones de los legati, vid. Salomonsson, 2000-2001; Gazzano, 2007; Torregaray Pagola, 2009.

4 Broughton, 1987.

5 Acerca del papel de los feciales y su evolución histórica, Auliard, 1992; Ferrary, 1993; Cimma, 2000; Santangelo, 2008.

6 Liv. Per. 51, $c f r$. Val. Max. 6.6.5, cit. en Broughton, 1987: 51.

7 Liv. 38.42.7, cf. Val. Max. 6.6.3, cit. en Broughton, 1987: 51-52.

8 Diod. Sic. 36.15, cit. en Broughton, 1987: 54-56.

9 Brennan, 2009.
} 
de misiones diplomáticas recogidas en De legationibus que terminaron en fracaso. Entre los diversos factores y causas de tal desenlace, se constatan algunos episodios de agresiones físicas contra los embajadores, caso, por ejemplo, del ataque de los ligures contra C. Flaminio ${ }^{10}$. El artículo de Brennan permite, en síntesis, contextualizar la violación del ius legationis en el marco general del fracaso diplomático y sus implicaciones. Se trata de un campo que presenta un enorme interés, según se puso de manifiesto en el coloquio organizado en 2012 por E. Torregaray $^{11}$, y que ha dado pie también a algunos artículos de reciente aparición, como el debido a Schettino, donde se presta especial atención al vocabulario empleado por las fuentes ${ }^{12}$.

La violencia - supuesta o real — contra los individuos en misión diplomática aparece, en efecto, como el detonante de numerosos conflictos protagonizados por la República romana. Al caso de los galos cisalpinos e ilirios, con sus agresiones contra embajadores y convenciones diplomáticas (c. 283 a. C.) $)^{13}$, se une el de los ataques a legados romanos por boyos e ínsubros $(218 \text { a. C. })^{14}$. De igual modo, en el ámbito norteafricano aparecen también noticias sobre agresiones cartaginesas contra emisarios romanos tras la Batalla de las Grandes Llanuras (203 a. C. $)^{15}$. Y el topos de la perfidia punica, prisma a través del cual debieran juzgarse tales apreciaciones, se hace extensivo a otros pueblos del norte de África como los númidas ${ }^{16}$. Desde la misma perspectiva de otredad, el cliché de la apistía griega nos deja alusiones a ataques contra otras misiones, caso de la supuesta violación del ius legationis en el 147 a. C., incidente utilizado como justificación de la destrucción de Corinto un año después ${ }^{17}$. Se trata de un lugar común que aparecerá más tarde en conexión con la violencia contra itálicos conocida como las Vísperas Asiáticas, del 88 a. C. ${ }^{18}$. Por su parte, el Bellum Gallicum ${ }^{19}$ cesariano nos proporciona también diversas menciones de supuestos atentados contra el ius legationis. Son reseñables especialmente el incidente de Ariovisto (58 a. C. $)^{20}$, la detención de Comio (55 a. C. $)^{21}$ y el episodio paradigmático de la acusación contra los Veneti por una transgresión del derecho de gentes (56 a. C.). ${ }^{22}$

Tomando en consideración los paralelos reseñados, nos centraremos en un problema singular: el de la atribución a Teuta — viuda del rey Agron y regente de Iliria (231-228 a. C.) ante la minoría de edad de su hijastro Pinnes ${ }^{23}$ de un atentado contra una embajada romana. El

10 Brennan, 2009: 180.

11 Gestionar el fracaso: algunas sombras de la diplomacia romana, celebrado en la Universidad del País Vasco (Departamento de Estudios Clásicos, Facultad de Letras) el 6-3-2012.

12 Schettino, 2017.

13 Polyb 2.18-19; Liv. Per. 12; App. Gall. 11 (Elg 5, p. 70); Sam. 6 (Elg 2, p. 68); Oros. 3.22.12-13; Bourdin, 2012; Fernández Palacios, 2016.

14 Polyb. 3.40.8-11; Liv. 21.25.1-7.

15 Polyb. 15.1.1-5; 15.2.4; 15.2.12-15; 15.3.1; 15.4.7-10; Liv. 30.23.6-7; App. Pun. 35; Cass. Dio en Zon. 9.13. Vid. Eckstein, 1987: 250-255.

16 Liv. 28.17.7; 29.23.6; Sall. Iug. 113, cfr. De Vallet, 1996; Poinssotte, 2002, entre una amplia bibliografía.

17 Liv. Per. 52.

18 Cic. Leg. Man. 11; Liv. Per. 78; Plin. HN 33.14; App. Mitr. 21. y 112; Diod. Sic. 37.27.

$19 C f r$. esp. Radin, 1916. Este importante trabajo encontraría sucesor muchas décadas más tarde, en la monografía de Szidat, 1970. Cfr. más recientemente Lamoine, 2011. Vid. discusión de este y los restantes casos del dossier cesariano en García Riaza, e. p.

20 Caes. BGall. 1.47.1-6; App. Gall. 17 (Elg 6, p. 71).

21 Caes. BGall. 4.27.2-4.

22 Caes. BGall. 3.7-9; 3.10.2; 3.16.4; Cass. Dio 39.40.1. A todos estos ejemplos de violencia cabe añadir aquellos correspondientes a agresiones sufridas por embajadores y otros negociadores a manos de sus propios conciudadanos, como represalia por mala gestión o a causa de existir sospechas de connivencia con el enemigo. Tal sería el caso de los embajadores púnicos del 149 a. C. (Polyb. 36.7.4-5; App. Pun. 92; Zon. 9.26.7), así como el del negociador numantino Avaro en 133 a. C. (App. Hisp. 95), objeto también de persecución local.

23 Cronología de Džino, 2010: XVII y 48. Sobre la expansión romana en la región, Petzold, 1971; Cabanes, 1988; Derow, 2003; Gračanin, 2005 et infra. 
suceso se ubicaría cronológicamente en el 230 a. C., y constituiría el detonante de la I Guerra Iliria, librada en los dos años siguientes. La especificidad de este episodio viene dada por cuanto, desde la perspectiva de las fuentes romanas, el casus belli del conflicto se relaciona no solo con la presunta violación iliria del ius legationis, sino con el elemento extra de agravio que supuso el hecho de que fuera una mujer la supuesta responsable de los crímenes.

Excede a los objetivos de este breve análisis un estudio en profundidad de las causas del conflicto, cuestión que ha sido ya abordada por diversos especialistas ${ }^{24}$. Nuestro propósito consiste en incidir en un aspecto del problema: el peso otorgado por las fuentes clásicas $-\mathrm{y}$ también por historiadores contemporáneos - al elemento de género a la hora de valorar los sucesos y otorgar credibilidad a determinadas versiones de los mismos. Se hace preciso, para ello, comenzar por un reexamen de la documentación antigua.

En las Historias de Polibio ${ }^{25}$, los ilirios en general y Teuta en particular son sistemáticamente presentados con tintes peyorativos ${ }^{26}$. La noticia de la crisis diplomática y la agresión contra la embajada viene precedida por un párrafo introductorio en el que se alude globalmente a la región como un foco de piratería. Tal actividad ilícita se estaría llevando a cabo por bandas fuera del control estatal, que tendrían como víctimas a numerosos mercaderes itálicos

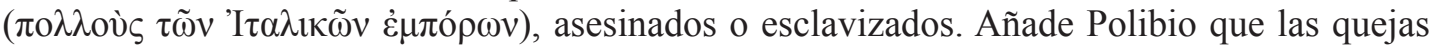
acerca de la situación venían de antaño, y que solo ahora, al intensificarse, llevaron al senado a actuar. Se decidió, así pues, el nombramiento de dos enviados encargados de realizar una

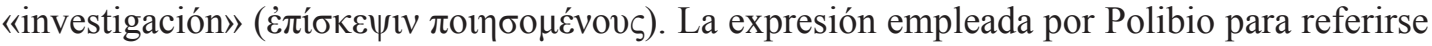

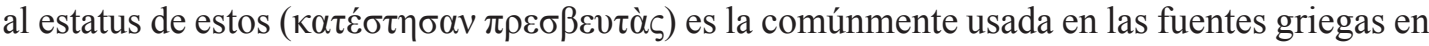
referencia a legati, por lo que no hay dudas sobre el carácter oficial, diplomático, de la misión. En este punto, nuestra fuente eleva en un grado la responsabilidad de Teuta, al indicar, ahora, que esta tenía deseos de llevar a cabo acciones depredatorias en las costas de Grecia. Polibio ofrece aquí, por tanto, un juicio de intenciones, preparando al lector para el relato de la tensa entrevista entre la regente y los embajadores romanos, que se iniciará con otra descalificación.

En efecto, establecido el momento para la audiencia, continúa Polibio, la mandataria iliria

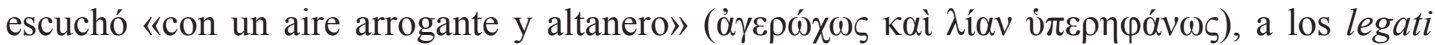
romanos - C. y L. Coruncanio-. Seguidamente, la propia Teuta habría tomado la palabra, afirmando que no era responsabilidad del Estado ilirio controlar las actividades privadas de aquellos que asaltaban naves en alta mar. La contrarréplica romana es atribuida por Polibio al más joven de los embajadores romanos - posiblemente $\mathrm{Lucio}^{27}$ — , quien, empleando un tono contundente, exigió a Teuta mayor control sobre sus súbditos ${ }^{28}$. Polibio cierra el párrafo con otra valoración denigratoria: «la reina se tomó estas palabras tan directas con un arrebato fe-

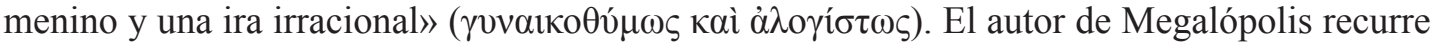
al verbo $\dot{\varepsilon} \xi$ o $\gamma \hat{\zeta} \zeta \omega$ para aludir a la furia de Teuta, que la condujo a «traspasar los límites del de-

24 Vid. acerca de esta cuestión Cabanes, 1983; Levi, 1973.

25 Polyb 2.8, cf. Plin NH 34.24, texto sobre el que volveremos más tarde. Vid. en general, acerca del tratamiento polibiano de la expansión romana en el Este, Derow, 1973 [2015] esp. 155 ss. en lo que respecta al conflicto con Teuta y la fabricación de un casus belli.

26 Eckstein, 1995; Džino, 2010: 47, sobre la necesidad de aproximarse a la obra de Polibio considerando su estructura narrativa (topos de barbarie y estereotipos culturales).

27 Si asumimos que la primera alusión polibiana a los embajadores se estableció con carácter jerárquico, siendo probablemente Cayo el princeps legationis. La conclusión — como tantas otras — ya está presente en De Sanctis, citado en los comentarios de Walbank, 1957: 159.

28 Se trata de un ejemplo de diplomacia coercitiva o «compelling diplomacy», en palabras de Eckstein, 2008: 40, quien no lo considera de especial dureza o excepcionalidad. Cfr. Marasco, 1987: 81: los embajadores romanos no plantean tanto un ultimátum como una petición de cese de la actividad pirática y de liberación de los mercaderes retenidos por los ilirios. 


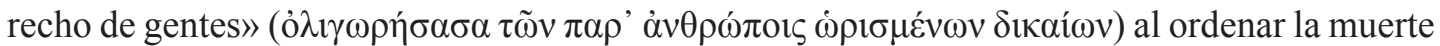
del legado romano en su travesía de regreso a Italia. El relato se construye en una dialéctica de causa-efecto, de modo que, sin solución de continuidad, Polibio describe la indignación

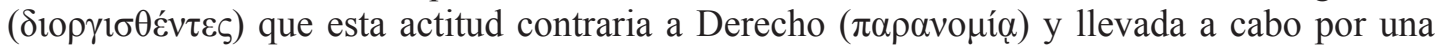

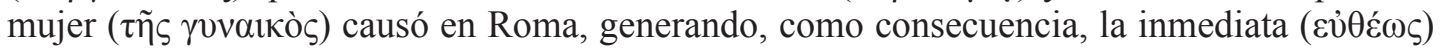
preparación de legiones y flota. Por lo que respecta a la presentación de los embajadores, la conexión polibiana entre juventud y atrevimiento o descaro merece, a nuestro juicio, una valoración cautelosa por su carácter igualmente tópico.

Lamentablemente, no conservamos el relato íntegro de Livio sobre estos sucesos. Sin embargo, las Periochae indican también que la guerra de Iliria fue declarada después de que uno de los embajadores fuera asesinado (unum ex legatis, qui ad eos missi erant, occisum $)^{29}$. En el texto, de nuevo, la conexión entre el ataque al legado y la declaración de guerra es directa. Por su parte, en Floro se reencuentran algunos de los elementos denigratorios ya empleados por Polibio $^{30}$. Destaca en el autor latino un uso muy evidente del género como elemento peyorativo (rasgo que ya vimos, más velado, en el de Megalópolis): Floro inicia su tratamiento del tema, precisamente, con tal indicación (regnante Teutana muliere), y añade de forma explícita que el crimen (scelus) resultó aún más indigno al haber sido cometido por una mujer: indignius foret, mulier imperavit. Se menciona como novedad el procedimiento de muerte (securi percussio, decapitación por hacha), y se indica que no solo fueron asesinados los legati, sino, cruelmente (igne), los praefecti navium. De igual modo, Orosio relaciona las agresiones y la guerra, calificando el conflicto como atrocissimum bellum ${ }^{31}$, y menciona la muerte no de uno, sino de «los emisarios» (legati Romanorum ab Illyriis interfecti sunt). Las fuentes latinas contribuyen, en definitiva, a la intensificación del discurso acerca del «crimen» ilirio.

Una versión radicalmente distinta de los acontecimientos es la proporcionada por Apiano en su Illyriké. Para el alejandrino, la responsabilidad de la agresión no recae en Teuta sino en su esposo Agrón..$^{32}$ Este, «rey de la parte de Iliria que bordea el Adriático», se había caracterizado por una política expansiva que le granjeó recelos en la región. La isla de Isa, una de las amenazadas, buscó la protección de Roma. Habría sido entonces cuando el senado envió una legación dirigida al rey que incorporó también a embajadores isios. La comitiva conjunta no llegaría finalmente a su destino, al ser atacada en ruta por naves ligeras ilirias de la clase lem$b_{o s}{ }^{33}$, con el resultado de la muerte de Kleémporo, embajador de los isios, y de Coruncanio, su homólogo romano ${ }^{34}$. Vemos, pues, que en Apiano la agresión se produjo antes de que los embajadores fueran recibidos en audiencia, aunque subsiste el dato de que el ataque se verificó en el mar. De acuerdo con su reconstrucción de los hechos, fue precisamente entonces cuando el rey Agrón murió, y Teuta pasó a ejercer como regente.

$\mathrm{Al}$ igual que en las restantes fuentes, la relación directa entre la agresión a los embajadores y la declaración de guerra es meridiana en Apiano: «por este hecho, los romanos emprendieron una expedición contra los ilirios por mar y tierra conjuntamente». En definitiva, para el escritor alejandrino el papel de Teuta fue secundario y, a ojos de Roma, positivo a medio plazo: una vez declarada la guerra y, ante la pérdida de numerosos enclaves y territorios que fueron pasándose a Roma, Teuta «envió embajadores a Roma para devolverles los prisioneros y los

\footnotetext{
29 Liv. Per. 20.

30 Flor. 1.21.2-3.

31 Sequenti anno legati romanorum ab Illyriis interfecti sunt. Post cum ipsis Illyriis atrocissimum bellum gestum est: in quo multis oppidis populisque deletis reliqui se fuluio postumioque consulibus dediderunt, Oros. 4.13.2.

32 Vid. Marasco, 1993; Šašel Kos, 2004; 2005; 2013; y, recientemente, Džino, 2016.

33 Džino, 2005.

34 App. Ill. 7.
} 
desertores y solicitó el perdón para lo que había ocurrido, no bajo su responsabilidad, sino la de Agrón», aceptando, finalmente, las condiciones restrictivas impuestas por Roma y suscribiendo un tratado ${ }^{35}$.

Por su parte, la versión de Dión Cassio, preservada en Zonaras ${ }^{36}$, constituye, en cierto modo, un relato híbrido ${ }^{37}$ en el que se otorga la responsabilidad inicial a Agrón (de manera análoga a Apiano), pero en el que se atribuye a Teuta la agresión contra los embajadores tras el discurso de estos (como ya vimos en Polibio). Así, los de la isla de Isa, que habían realizado una deditio in fidem a Roma por el malestar ante el expansionismo de Agrón, suscitaron el envío desde Italia de una legatio al mencionado rey, que falleció por entonces. La embajada fue ya recibida por la regente, Teuta, quien, al escuchar la franqueza — «insolente»— con la que se expresó alguno de los emisarios, decidió enviar a prisión a ciertos legati, y asesinar a otros. La consecuencia directa - una declaración de guerra por parte de Roma - habría sido recibida, sin embargo, con pánico por Teuta. Esta optó por una política contemporizadora, ofreciéndose a devolver a los encarcelados, y atribuyendo la muerte de los otros legati a bandidos (de donde se deduce que la agresión se produjo, de algún modo, in itinere). Pero cuando Roma demandó la entrega de los asesinos, Teuta se negó, con el resultado del recrudecimiento del conflicto. No están ausentes, tampoco aquí, las valoraciones misóginas, en este caso referidas a la supuesta volubilidad femenina. Así, tras la declaración de guerra por parte de Roma, Teuta solicita una tregua, pero luego cambia de parecer y se muestra hostil, atribuyendo nuestra fuente esta mutabilidad a su condición de mujer.

Es evidente concluir, en este punto, como escribiera Gruen, que «our sources conflict». ${ }^{38}$ Las fuentes de Polibio y Apiano son, sin lugar a dudas, distintas. En general, no debe ocultarse la predilección de los historiadores modernos por las versiones polibianas en casos de discrepancia. En el ámbito particular de las noticias sobre los orígenes de la I Guerra Iliria - recuerda Džino, en su interesante balance historiográfico — ${ }^{39}$, fue esta, precisamente, la interpretación privilegiada por los primeros estudiosos de la cuestión. Pero Polibio, en este caso, suscita dudas de fiabilidad: es preciso tener en cuenta, como se ha señalado ${ }^{40}$, que el propio autor de Megalópolis reconoce que sus fuentes para esta época son diferentes (y sin duda, de peor calidad) que las empleadas para los hechos posteriores al 220 a. C. Por ello, no resulta sorprendente que la historiografía contemporánea se muestre dividida, habiendo basculado, hasta cierto punto, en favor de Apiano. Entre los principales valedores de la versión apianea se encuentra Derow, autor de un influyente artículo en el que confirma que el antropónimo $\mathrm{K} \lambda \varepsilon \varepsilon \dot{\varepsilon} \mu \pi \mathrm{o} \rho \varsigma$ usado por Apiano tiene paralelos epigráficos en la región. Esta constatación, obviamente, no posee valor probatorio en lo que respecta a la reconstrucción de los acontecimientos $^{41}$, pero sí constituye un indicio de la utilización por el autor de Alejandría de material genuino $^{42}$. De igual forma, Šašel Kos considera que el relato de Apiano es «more objective» ${ }^{43}$. Frente a esta opinión, otros destacados especialistas contemporáneos abordan el texto apianeo

35 App. Ill. 8.

36 Cass. Dio fr. 49.3 (Zon. 8.19). Vid. Simons, 2009.

37 Hammond 1968: 5-6, n. 16; Derow 1973 [2015]: 151, n. 2.

38 Gruen, 1984: 359-368.

39 Džino, 2010: 47-50.

40 Derow, 1973 [2015]: 155, en referencia a Polyb. 4.2.2-3: tradiciones de segunda o tercera mano.

41 Ver, en este sentido, las críticas de Harris, 1979: 195-196, n. 4: «Appian's version is a clumsy abbreviation, probably at a second hand, of a reasonably good source that was probably more detailed, but more pro-Roman, than Polybius». Cfr. Hornblower, 2000: 143.

42 Derow, 1973 [2015]; 2003: 51-53, a partir de Grant, 1965. Vid. Šašel Kos, 2004: 150, aceptando el planteamiento de Derow en favor de la historicidad de la participación de embajadores de Isa.

43 Šašel Kos, 2004: 178; 2013: 178. 
tomando bastante más distancia. Con fina ironía, ya Hammond — que firma uno de los análisis más cuidadosos y sistemáticos en relación con el caso que nos ocupa- puso en tela de juicio la versión del alejandrino ${ }^{44}$, pero manifiesta también su escepticismo sobre algunos detalles del relato de Polibio, al que considera irreconciliable con el anterior ${ }^{45}$. Y anota: «The statement of Polybius that Teuta instigated the assassination should not therefore be accepted as necessarily true», señalando que el texto se orienta a mostrar a la reina iliria como la responsable de la quiebra del ius gentium ${ }^{46}$. Por su parte, Marasco, en su detallado estudio sobre las razones de fondo para la guerra ilírica, otorga, no sin matices, credibilidad a la versión polibiana en lo que respecta a las conversaciones, pero, en cuanto al atentado contra la embajada, indica: «È credibile che tale atto non sia stato ordinato da Teuta e che l'attribuzione a lei di tale ordine corrisponda alle esigenze della propaganda romana $»^{47}$. El debate historiográfico permanece abierto, como se pone de manifiesto en los trabajos publicados durante los últimos años. Así Džino califica el libro de Apiano como «colonial artifact», y considera que la Illyriké es, probablemente, el más artificial de los constructos geopolíticos presentados por el historiador de Alejandría ${ }^{48}$. Para Džino, Octaviano es el único «héroe» real de la obra, de modo que el autor evita presentar de manera elaborada retratos de otros personajes, como Teuta o Demetrio de Faros. Pero añade también que estos últimos aparecen en la historiografía previa a Apiano (incluyendo, por tanto, el relato de Polibio) como «colourful literary characters ${ }^{49}$. Desde nuestro punto de vista, una de las valoraciones más equilibradas a la hora de reconstruir el supuesto atentado contra el ius legationis continúa siendo la de Gruen, quien no se decanta por una explicación taxativa, concluyendo que nos hallamos ante «various irreconciliable versions» ${ }^{50}$. En su opinión, puede asumirse que, en efecto, un miembro de la misión pereciera, pero la imputación de responsabilidad a Teuta constituiría una invención ex post facto. Tampoco acepta que la embajada estuviera provocada por una petición de los isleños de Isa. La explicación más económica, a su juicio, es que el rey ilirio se encontrara entonces en la isla, y que hacia allí se dirigiera por ello la legatio romana que reclamaba seguridad marítima. Gruen considera el peso de las quejas de los mercaderes itálicos, pero no va más allá a la hora de dilucidar el problema del atentado a la embajada, alegando que las noticias a las que accedieron nuestros informantes carecían ya de concreción. ${ }^{51}$ Por lo que respecta a la valoración de las referencias de género en las fuentes, señala: «The portrait of the explosive, unreasoning woman who yielded to her emotions and threw a female tantrum is plainly rhetorical, exaggerated for literary effect». ${ }^{52}$ Una interpretación que, en esencia, hallamos ya en Harris. Para este, el «sexist comment» de Polibio estaba orientado a hacer plausibles los cargos contra Teuta, cuando,

44 «A fine case of Rome protecting a little Greek state and Rome wronged by the wicked Illyrians!», Hammond 1968: 5-6 n. 16. Vid. también Walbank, 1957: 159, criticando la aceptación por De Sanctis de la versión analística: «looks like an example of the old legend that the Romans waged only iusta bella, and generally to defend allies»».

45 Hammond, 1968: 5-6 n. 16, negando la posibilidad de que Polibio tuviera acceso al contenido literal del diálogo diplomático.

46 Hammond, 1968: 5-6 n. 16.

47 Marasco, 1987: 90. Y añade que el atentado, a pesar de generar una oleada de indignación en Roma, no constituyó el motivo de fondo para la intervención, que debe buscarse en el efecto pernicioso de la piratería sobre los intereses comerciales itálicos.

48 Džino, 2016: 74.

49 Džino, 2016: 77 y n. 50, remitiendo al conocido trabajo de Gómez Espelosín, 1993 sobre la imagen del «bárbaro» en Apiano.

50 Gruen, 1984: 361.

51 «Clearly, the story lacked firm basis», Gruen, 1984: 361.

52 Gruen, 1984: 361. 
en realidad, su réplica a los embajadores fue razonable ${ }^{53}$. En síntesis, asumiendo que las circunstancias permanecen oscuras, puede reconocerse la elaboración de un relato de consumo interno romano en el que la política expansiva de la República se justifica como respuesta, una vez más, a violaciones del ius legationis.

A los testimonios literarios hasta aquí considerados cabe añadir una referencia debida a Plinio el Viejo ${ }^{54}$ no suficientemente valorada, a nuestro juicio, que permite abundar en la hipótesis de la instrumentalización de los hechos. El autor erudito, a propósito de la identificación de los primeros personajes homenajeados en Roma mediante estatuaria, refiere dos monumentos de extraordinaria significación. Plinio alude, en primer lugar, a las estatuas erigidas en recuerdo de los emisarios romanos (438 a. C.) asesinados por los fidenates: inter antiquissimas sunt et Tulli Cloeli, L. Rosci, Sp. Nauti, C. Fulcini in rostris, a Fidenatibus in legatione interfectorum $^{55}$. El autor de la Historia Natural justifica la dedicación del monumento indicando que era una práctica romana honrar a los asesinados contra Derecho: hoc a re $p$. tribui solebat iniuria caesis. Seguidamente - y este es el dato que nos interesa aquí-, señala que tal era el caso, igualmente, de las estatuas en honor de P. Junio y Ti. Coruncanio, los embajadores romanos «asesinados por Teuta»: sicut aliis et P. Iunio, Ti. Coruncanio, qui ab Teuta Illyriorum regina interfecti erant. En general, como indica Derow ${ }^{56}$, debe reconocerse que el pasaje de Plino deja bastante que desear en cuanto a la precisión de sus datos. Para comenzar, existe una discrepancia sobre el número de víctimas romanas. La referencia dual de Plinio coincide grosso modo con los datos de Floro, Dión Cassio y Orosio, que aluden a «embajadores». Sin embargo - aquí radica la principal dificultad-, tanto Polibio como las Periochae de Livio o Apiano apuntarían a un solo enviado senatorial asesinado. Cabe preguntarse, por tanto, acerca del grado de historicidad que debemos otorgar al texto de Plinio. Para Derow, la única identificación asumible sería la de Coruncanio (cuyo praenomen debería corregirse a la luz de Polibio), en tanto que la mención de P. Junio, carente de refrendo en otras fuentes, tendría que descartarse por errónea. En cualquier caso, no hay argumentos para dudar de la existencia del monumento. Plinio se habría basado, según él mismo declara, en ciertos annales, que darían fe de algunos datos concretos, como el tamaño y la ubicación de las estatuas ${ }^{57}$. La fecha ante quem para la iniciativa de homenaje público se encuentra en relación directa con la fuente pliniana, cuya identificación debe realizarse con prudencia. Si asumimos una relación con los annales maximi, la estatua o las estatuas se habrían erigido con anterioridad al pontificado de P. Mucio Escévola (130-115 a. C.), momento en que, según Rodríguez Mayorgas, los anales habrían dejado de redactarse ${ }^{58}$. Esta impresión se reforzaría si consideramos que la introducción de todo el párrafo pliniano (inter antiquissimas...) se refiere también a las estatuas de Iliria. Desde nuestro punto de vista, el monumento a la víctima (o las víctimas) del atentado contra el ius legationis en Iliria constituye una manifestación tangible y plástica de la elaboración en época republicana (acaso en un momento no muy posterior a los acontecimientos del 230 a. C.) de un relato oficial sobre las razones para la guerra. Sin que podamos determinar

53 Harris, 1979: 195 nn. 3-4. Y añade (n. 4): «Appian aberration (...) is easy to explain as an annalist tale designed to stregthen Rome's retrospective case for intervention» (cfr. en la misma línea, Walbank, 1957: 153, sobre Apiano: «well informed on Illyria, but contaminated by annalistic inventions»). En general Harris se muestra más inclinado a dar credibilidad a la versión polibiana. Reconoce la muerte del embajador, pero no necesariamente la responsabilidad de Teuta.

54 Plin $N H 34.24$.

55 Cfr., junto al citado pasaje pliniano, Cic. Phil. 9.5: a Veientium rege caesi sunt; Liv. 4.17.2-6: legatos Romanos, causam novi consilii quaerentes, iussu Tolumni interfecerunt; Broughton, 1951: 58.

56 Derow, 1973 [2015]: 155 y n. 14.

57 non omittendum videtur, quod annales adnotavere, tripedaneas iis statuas in foro statutas; haec videlicet mensura honorata tunc erat.

58 Rodríguez Mayorgas, 2007: 266. 
con certeza el papel que, en tal discurso, los contemporáneos romanos otorgaron a Teuta, la lectura de Plinio ( $a b$ Teuta... interfecti) podría emanar, en última instancia — entrando en el terreno de la hipótesis-, de la interpretación originaria del monumento, escultura que estaría complementada por un texto epigráfico.

Pese a que, según hemos intentado poner de manifiesto, la responsabilidad de la mandataria iliria en las agresiones a legati dista mucho de poder atribuirse sin reservas, la versión polibiana, amplificada después por Floro, que presenta una Teuta irascible y agresiva, ha atraído, casi magnéticamente, a un sector no poco influyente de la historiografía moderna. Así, una de las obras imprescindibles para cualquier republicanista, Magistrates of the Roman Republic, de 1951, presenta a los legati C. Coruncanius, L. Coruncanius y P. Iunius con el siguiente comentario: «Murder of one of these, L. Coruncanius, by Queen Teuta of the Illyrians was the incident which provoked the Illyrian war ${ }^{59}$. Esta es la versión que ha venido trascendiendo también en representaciones artísticas, como el elocuente grabado (Fig. 1) debido a Augustyn Mirys (1700-1790). Esperamos que el texto que aquí concluye haya proporcionado, al menos, elementos para invitar a la reflexión en torno al escollo de los prejuicios de género en el siempre complejo y tributario de su época - análisis del pasado clásico.

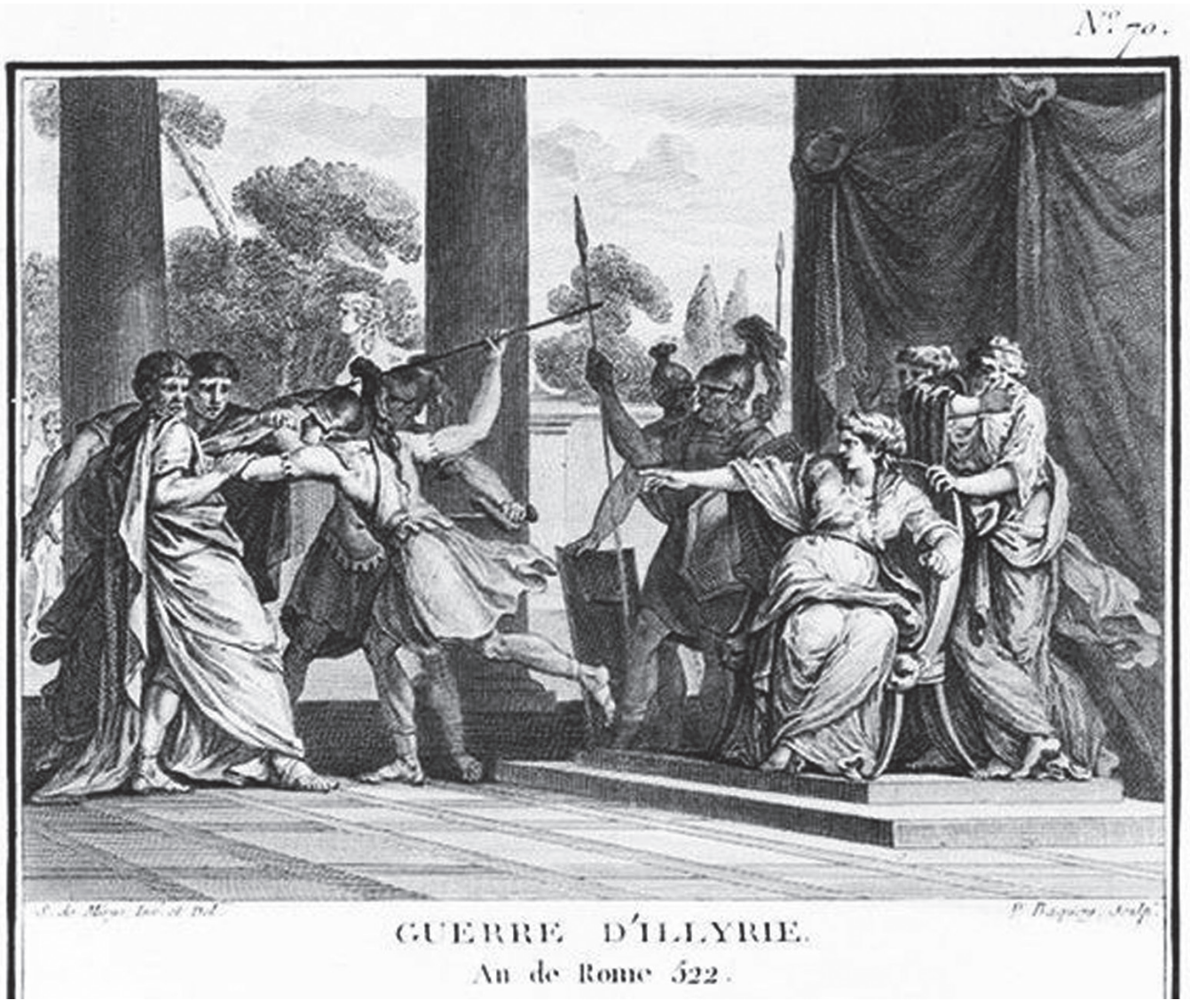

Figura 1. «Guerre d'Illyrie», grabado de Augustyn Mirys (1700-1790).

Fuente: Wikimedia Commons.

\footnotetext{
59 Broughton, 1951: 227. Cabe señalar, por otra parte, que se incurre en la contradicción de asumir la referencia pliniana a P. Junio negando en paralelo la muerte de este. Cfr. Wilkes, 1992: 159-160.
} 


\section{BIBLIOGRAFÍA}

Auliard, C. (1992): «Les fétiaux, un collège religieux au service du droit sacré international ou de la politique extérieure romaine?». Mélanges P. Lévèque, 6. Paris, Université de Franche-Comté-Les Belles Lettres: 1-16.

Bederman, D. J. (2001): International Law in Antiquity. Cambridge, Cambridge University Press.

Bourdin, S. (2012): Les peuples de l'Italie préromaine. Identités, territoires et relations inter-ethniques en Italie Centrale et Septentrionale (VIII ${ }^{e} \mathrm{I}^{e r}$ s. av. J.-C.). BEFAR, 350. Rome, École française de Rome.

Boyancé, P. (1964): «Les romains, peuple de la fides». Bulletin de l'Association Guillaume Budé : Lettres d'Humanité, 23/4: 419-435.

Brennan, T. C. (2009): «Embassies Gone Wrong: Roman Diplomacy in the Constantinian Excerpta de legationibus», C. Eilers (ed.), Diplomats and Diplomacy in the Roman World. Leiden - Boston, Brill: 171-191.

Broughton, T. R. S. (1951): The Magistrates of the Roman Republic. Volume 1: 509 B.C. - 100 B.C. New York, American Philological Association.

Broughton, T. R. S. (1987): «Mistreatment of Foreign Legates and the Fetial Priests: Three Roman Cases». Phoenix, 41: 50-62.

Cabanes, P. (1983): «Notes sur les origines de l'intervention romaine sur la rive orientale de la mer Adriatique (229-228 av. J.-C.)». Tarento, Istituto per la storia e l'archeologia della Magna Grecia: 187-204.

Cabanes, P. (1988): Les Illyriens de Bardylis à Genthios (IV-II siècles avant J-C). Paris, SEDES.

Cimma, M. R. (2000): «I feziali e il diritto internazionale antico». Ius Antiquum = Drevnee Pravo, 6: 24-31.

De Vallet, P. (1996): «Perfidia plus quam Punica: l'image des Carthaginois dans la littérature latine, de la fin de la République à l'époque des Flaviens». Lalies, 16: 17-28.

Derow, P. S. (1973): «Kleemporos». Phoenix, 27: 118-134 [art. recogido en A. Erskine y J. C. Queen, (eds.) (2015), Rome, Polybius \& the East. Oxford - New York, Oxbow Books: 151-167].

Derow, P. S. (2003): «The Arrival of Rome: From the Illyrian Wars to the Fall of Macedon», A. Erskine (ed.): A Companion to the Hellenistic World. Oxford, Blackwell: 51-70.

Džino, D. (2005): «The influence of Dalmatian shipbuilders on the ancient warships and naval warfare: the lembos and liburnica». Diadora : glasilo Arheološkog muzeja u Zadru, 21: 19-36.

Džino, D. (2010): Illyricum in Roman Politics. Cambridge University Press, Cambridge.

Džino, D. (2016): «Appian's Illyrike: The final stage of the Roman construction of Illyricum». Straživanja. Journal of Historical Researches, 27: 69-83.

Eckstein, A. M. (1987): Senate and General: Individual Decision-making and Roman Foreign Relations, 264-194 B.C. Berkeley - Los Angeles - London, University of California Press.

Eckstein, A. M. (1995): Moral Vision in "The Histories" of Polybius. Berkeley - Los Angeles - London, University of California Press.

Eckstein, A. M. (2008): Rome Enters the Greek East: From Anarchy to Hierarchy in the Hellenistic Mediterranean, 230-170 BC. Malden, MA, Wiley-Blackwell.

Fernández Palacios, F. (2016): «Celtas contra romanos en Italia a inicios del siglo III a.C. Desentrañando la batalla de Arretium, la fundación de la colonia Sena Gallica and all that», G. Bravo y R. González Salinero (eds.), XIII Coloquio de la AIER. Crisis en Roma y soluciones desde el poder. Madrid - Salamanca, Signifer Libros: 123-139.

Ferrary, J. L. (1993): «Ius fetiale et diplomatie», E. Frézouls y A. Jacquemin (eds.), Les relations internationales. Actes du Colloque du Strasbourg 15-17 juin 1993. Paris, De Boccard: 411-432.

García Riaza, E. (e. p.): «La supuesta contravención del ius legationis en el Bellum Gallicum», E. Torregaray Pagola y J. Lanz Betelu (eds.), Algunas sombras en la diplomacia romana, Anejos de Veleia. Series Minor, 38. Vitoria, Servicio Editorial de la Universidad del País Vasco.

Gazzano, F. (2007): «Présbeis/presbeutaí e legati fra mondo greco e romano», M. Mayer Olivé; G. Baratta y A. Guzmán Almagro (eds.), Acta XII Congressus Internationalis Epigraphiae Graecae et Latinae: Provinciae Imperii Romani inscriptionibus descriptae : Barcelona, 3-8 Septembris 2002. Barcelona, Institut d'Estudis Catalans, Universitat de Barcelona, Universitat Autònoma de Barcelona: 575-580.

Gómez Espelosín, F. J. (1993): «La imagen del bárbaro en Apiano. La adaptabilidad de un modelo retórico». Habis, 24: 105-124. 
Gračanin, H. (2005): «Illyricum of the 2nd and 3rd centuries AD in the works of Latin and Greek historians», M. Šegvić y I. Mirnik (eds.), Illyrica Antiqua. Ob honorem Duje Rendić-Miočević.Zagreb, F.F. Press: 287-298.

Grant, J. R. (1965): «A Note on the Tone of Greek Diplomacy». The Classical Quarterly, 15/2 (Nov.): 261-266.

Gruen, E. S. (1984): The Hellenistic World and the Coming of Rome. Berkeley - Los Angeles - London, University of California Pres.

Hammond, N. G. L. (1968): «Illyris, Rome and Macedon in 229-205 B.C.». Journal of Roman Studies, 58/1-2: 1-21.

Harris, W. V. (1979): War and Imperialism in Republican Rome, 327-70 B. C. Oxford-New York, The Clarendon Press-Oxford University Press.

Hornblower, S. (2000): «Personal Names and the Study of the Ancient Greek Historians», S. Hornblower y E. Matthews (eds.), Greek Personal Names. Their Value as Evidence. Oxford, Oxford University Press: 129-143.

Lamoine, L. (2011): «Recherches actuelles en France sur les inter-relations romano-gauloises», E. García Riaza (ed.), De fronteras a provincias. Interacción e integración en Occidente (ss. III-I a.C.). Palma, Edicions UIB: 123-139.

Levi, M. A. (1973): «La causa della Guerra romana contro gli Illiri». La Parola del Passato, 152: 317-325.

Marasco, G. (1987): «Interessi commerciali e fattori politici nella condotta romana in Illiria (230-219 a.C.)». Studi Classici e Orientali, 36: 35-112.

Marasco, G. (1993): «L'Illyriké di Appiano». Aufstieg und Niedergang der römischen Welt, 2.34.1: 463-495.

Petzold, K.-E. (1971): «Rom und Illyrien. Ein Beitrag zur römischen Außenpolitik im 3. Jahrhundert». Historia, 20: 199-223.

Philipson, C. (1911): The International Law and Custom of Ancient Greece and Rome, I. London, Macmillan and Company.

Poinssotte, J. M. (2002): «L'image du carthaginois à Rome», C. Briand-Ponsard y S. Crogiez-Pétrequin (eds.), L'Afrique du Nord antique et médiévale: mémoire, identité et imaginaire. Rouen, Presses universitaires de Rouen et du Havre: 77-86.

Radin, M. (1916): «The International Law of the Gallic Campaigns». The Classical Journal, 12/1: 8-33.

Rodríguez Mayorgas, A. (2007): «Antes de la historia: Anales Máximos, escritura memoria en la Roma Republicana». Gerión 25/1: 263-284.

Salomonsson, M. M. (2000-2001): «Roman Legates in the Republic». Opuscula Romana, 25-26: 79-88.

Santangelo, F. (2008): «The Fetials and their Ius». Bulletin of the Institute of Classical Studies, 51/1: 63-93.

Šašel Kos, M. (2004): «The Roman Conquest of Illyricum in Light of Appian's Illyrike», G. Urso (ed.), Dall'Adriatico al Danubio: L'Illirico nell'età greca e romana. Pisa, ETS: 141-166.

Šašel Kos, M. (2005): Appian and Illyricum. Situla 43, Ljubljana.

Šašel Kos, M. (2013): «The Roman Conquest of Illyricum (Dalmatia and Pannonia) and the Problem of the Northeastern Border of Italy». Studia Europaea Gnesnensia, 7: 169-200

Schettino, M. T. (2017): «L'échec diplomatique existe-t-il pour les romains ? Réflexions sur cette notion et sa représentation à la fin de la République». Dialogues d'Histoire Ancienne, 43/1: 151-173.

Simons, B. (2009): Cassius Dio und die Römische Republik. Untersuchungen zum Bild des römischen Gemeinwesens in den Büchern 3-35 der "Romaika". Berlin-New York, De Gruyter.

Szidat, J. (1970): Caesars diplomatische Tätigkeit im Gallischen Krieg. Historia Einzelschr. XIV. Wiesbaden, Franz Steiner Verlag.

Torregaray Pagola, E. (2009): «Legatorum facta: la ejemplaridad de los embajadores romanos». Veleia, 26 (dossier monográfico: Puesta en escena y escenarios en la diplomacia del mundo romano): 127-152.

Walbank, F. W. (1957): A Historical Commentary on Polybius, Vol. I, Commentary on Books I-VI. Oxford, The Clarendon Press.

Wilkes, J. (1992): The Illyrians. Oxford-Cambridge, MA, Blackwell.

Recibido: 16-06-2019

Aceptado: 20-03-2020

Gladius, XL (2020), pp. 7-17. ISSN: 0436-029X; eISSN: 1988-4168. https://doi.org/10.3989/gladius.2020.01 